PAPER

\title{
Discrimination of Japanese fricatives and affricates by production bound- aries in time and spectral domains: A case study of a female native speaker
}

\author{
Kimiko Yamakawa* and Shigeaki Amano ${ }^{\dagger}$ \\ Aichi Shukutoku University, 2-9 Katahira, Nagakute, Aichi, 480-1197 Japan
}

(Received 16 April 2014, Accepted for publication 2 December 2014)

\begin{abstract}
Acoustic features of fricatives (/s/ and /6/) and affricates (/ts/ and / t $6 /$ ) spoken by a female native speaker of Japanese were investigated. Discriminant analysis in the time domain revealed that fricatives $(/ \mathrm{s} /$ and $/ 6 /)$ and affricates (/ts/ and / t $/$ /) are well separated at a discriminant ratio of $98.0 \%(n=508)$ when using the variables of the rise duration and the sum of steady and decay durations of the consonants' intensity envelope. Discriminant analysis in the spectral domain revealed that alveolar consonants (/s/ and / ts/) and alveolo-palatal consonants (/6/ and / $\left.\mathrm{t}_{6} /\right)$ are well separated at a discriminant ratio of $99.2 \%(n=508)$ when using the variable of the mean intensity of one-thirdoctave bandpass filter with a center frequency of $3,150 \mathrm{~Hz}$. In addition, the four consonants were correctly identified at an accuracy rate of $97.2 \%(n=508)$ when using a combination of production boundaries obtained in the above two discriminant analyses. Results suggest that the acoustic features of the four consonants can be represented by the time- and spectral-domain variables described above.
\end{abstract}

Keywords: Fricative, Affricate, Production boundary, Discriminant analysis

PACS number: 43.70.Fq, 43.70.Bk [doi:10.1250/ast.36.296]

\section{INTRODUCTION}

Although alveolar fricative /s/, alveolo-palatal fricative /6/, alveolar affricate /ts/, and alveolo-palatal affricate / 6 / are distinctive in Japanese when they precede vowel $/ \mathrm{u} /$, they have similar acoustic features. Each phoneme consists of frication, and two of them, the affricates /ts/ and / to/, contain a burst at the beginning of frication. Owing to their similar acoustic features, it is difficult for non-native speakers of Japanese, such as speakers whose native tongue is Korean or Thai, to pronounce these consonants with clear distinction (e.g., [1-3]).

Despite the similarities contained within the consonants, they are distinguished through certain acoustic features (e.g., [4-9]). For example, Strevens [4] showed that in English, the spectral peak is higher in /s/ (about $3500 \mathrm{~Hz})$ than in $/ \int /(1,600-2,500 \mathrm{~Hz})$. Jongman et al. [5] and Maniwa et al. [6] showed that a spectral peak, a spectral moment, and a normalized and relative amplitude contribute to the discrimination of English fricatives. Howell and Rosen [7] showed that, in English, the frication rise time of $/ \mathrm{t} /$ is shorter than that of $/ \mathrm{f} /$.

Yamakawa et al. [8] studied discrimination of Japanese /s/ and /ts/ in the time domain. In their study, /s / and /ts/

*e-mail: jin@asu.aasa.ac.jp

†e-mail: psy@asu.aasa.ac.jp were divided into three parts (rise, steady, and decay), and the intensity envelope of the rise, steady, and decay parts was approximated by three lines with positive, zero, and negative slopes, respectively. From these approximated lines, the durations of the rise, steady, and decay parts were calculated. From the discriminant analysis using these durations, Yamakawa et al. [8] demonstrated that /s/ and /ts/ are well separated by a combination of the rise duration and the sum of steady and decay durations.

As for /ts/ and / t6/ in Japanese, Yamakawa and Amano [9] conducted discriminant analysis in the spectral domain. In their study, /ts/ and / t6/ were input into the one-third-octave bandpass filters that had different center frequencies, and the mean intensity was calculated for each bandpass filter. Yamakawa and Amano [9] revealed that /ts/ and / 6 / are well separated with the mean intensity of the one-third-octave bandpass filter with a center frequency of $3,150 \mathrm{~Hz}$. They also conducted discriminant analysis for /s/ and /ts/, and reported that /s/ and /ts/ cannot be separated by the mean intensity of the one-third-octave bandpass filter with a center frequency of $3,150 \mathrm{~Hz}$. In addition, Yamakawa and Amano [9] suggested that different manners of articulation (e.g., fricative vs affricate) are related to differences in the time-domain variable, whereas different places of articulation (e.g., alveolar vs alveolopalatal) are related to differences in the spectral-domain variable. 
Although several findings were accumulated in previous studies, unsolved problems concerning the discrimination of fricatives and affricates remain. For instance, acoustic features in the discrimination of Japanese /6/ have not been well investigated. However, on the basis of the above suggestion made by Yamakawa and Amano [9], we predict that, with respect to the time-domain variable, $/ 6 /$ can be discriminated from $/ \mathrm{ts} /$ and $/ \mathrm{t} 6 /$, but not from $/ \mathrm{s} /$, because the fricative $/ 6 /$ differs in the manner of articulation from the affricates $/ \mathrm{ts} /$ and $/ \mathrm{t}_{6} /$, but it has the same manner of articulation as the fricative $/ \mathrm{s} /$. We also predict that, with regard to the spectral-domain variable, $/ 6 /$ can be discriminated from $/ \mathrm{s} /$ and $/ \mathrm{ts} /$, but not from $/ t_{6} /$, because the alveolo-palatal consonant $/ 6 /$ has a different place of articulation from the alveolar consonants $/ \mathrm{s} /$ and $/ \mathrm{ts} /$, but the same place of articulation as the alveolo-palatal consonant $/ \mathrm{t}_{\mathrm{c}} /$.

Another issue concerning fricatives and affricates is that previous studies limit their investigation of discrimination to individual consonant pairs, such as /s/ vs /ts/ or /ts/ vs / t $6 /$. To obtain an integrated view of acoustic features of the four consonants, an examination of discrimination between consonant groups, such as fricatives vs affricates or alveolar vs alveolo-palatal consonants, is necessary.

Moreover, if we also consider speech-education applications, the distinction of consonant groups is insufficient. For speech-education applications, scientific knowledge and concrete values of discriminant variables are required so that we will be able to automatically identify each consonant produced by non-native speakers of Japanese.

With these considerations in mind, in the present study, we examined the following points as the first step in solving the remaining problems.

The first aim of the research was to examine whether alveolo-palatal fricative $/ 6 /$ is well separated from the affricates (/ts/ and / to/) with respect to time-domain variables, but not a spectral-domain variable, and whether $/ 6 /$ is well separated from the alveolar consonants (/ts/ and $/ \mathrm{s} /$ ) with respect to the spectral-domain variable, but not time-domain variables.

The second aim of this study was concerned with the discrimination in a group of four consonants: /s/, / $/$ /, /ts/, and $/ \mathrm{t}_{6} /$. We examined whether fricatives $(/ \mathrm{s} /$ and $/ 6 /)$ and affricates (/ts/ and / t $6 /$ ) are well separated by a variable in the time domain, and whether alveolar consonants (/s/ and /ts/) and alveolo-palatal consonants $\left(/ 6 /\right.$ and $\left./ t_{6} /\right)$ are well separated by a variable in the spectral domain.

The third aim of this study was to examine whether the four consonants (/s/, / $/, / \mathrm{ts}_{\mathrm{s}} /$, and $\left./ \mathrm{t}_{6} /\right)$ are well identified using a combination of production boundaries in the time and spectral domains.

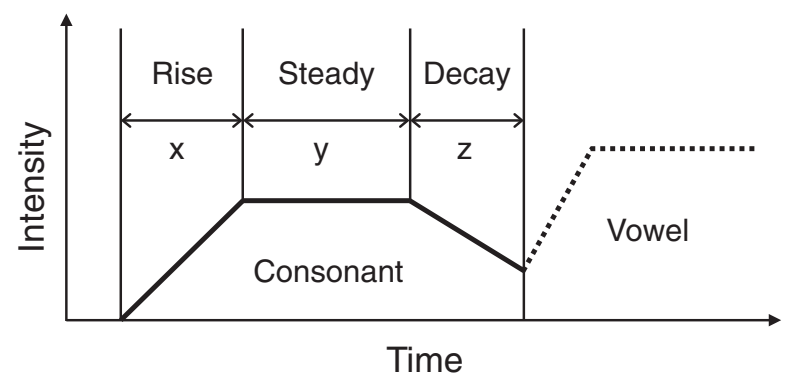

Fig. 1 Schematic diagram of intensity envelope. $x, y$, and $z$ respectively represent durations of rise, steady, and decay parts.

For achieving these aims, discriminant analyses in the time and spectral domains were conducted using speech material containing $/ \mathrm{s} /, / 6 /, / \mathrm{ts} /$, and $/ \mathrm{t}_{6} /$ selected from the Japanese database [10] in this study.

\section{TIME-DOMAIN ANALYSIS}

\subsection{Speech Materials}

Speech materials consisted of Japanese spoken words selected from the Japanese word familiarity database [10], which contains about 70,000 words read at a normal speaking rate by a 29 -year-old female Japanese native speaker who was a well-trained narrator. The spoken words in the database are stored as digital audio files with 16-bit quantization and $16 \mathrm{kHz}$ sampling frequency. The selection criteria were as follows:

1) $/ \mathrm{s} /, / 6 /, / \mathrm{ts} /$ or $/ \mathrm{t}_{6} /$ is in the word-initial position;

2) an undevoiced vowel $/ \mathrm{u} /$ follows $/ \mathrm{s} /, / 6 /, / \mathrm{s} /$, or $/ t_{6} /$;

3) word length is three or four morae.

The vowel $/ \mathrm{u} /$ always follows $/ \mathrm{ts} /$ in Japanese whereas other vowels can follow $/ \mathrm{s} /, / 6 /$, and $/ \mathrm{t} 6 /$. To control unexpected effects of the following vowels, the second condition above was introduced. Because the database contains many three- and four-mora words that satisfy these three criteria, qualifying words were selected at random. The final number of chosen words was 127 (22 three-mora words, 105 four-mora words) for each of the consonants $/ \mathrm{s} /, / 6 /$, $/ \mathrm{ts} /$ and $/ \mathrm{t}_{6} /$. There were 508 words in total (127 words $\times 4$ consonants).

\subsection{Procedure}

With respect to time domain analysis, we followed the method that proposed by Yamakawa et al. [8]. By the automatic fitting method [8], polygonal lines were fitted for the intensity envelope of the rise, steady, and decay parts of $/ \mathrm{s} /, / 6 /, / \mathrm{s} /$, and $/ \mathrm{t}_{6} /$ in the speech materials (Fig. 1). The rise duration $x$ and the sum of steady and decay durations $y+z$ were identified from the fitted polygonal lines.

Discriminant analyses were conducted for each combination of two consonants from among $/ \mathrm{s} /, / 6 /, / \mathrm{ts} /$, and 


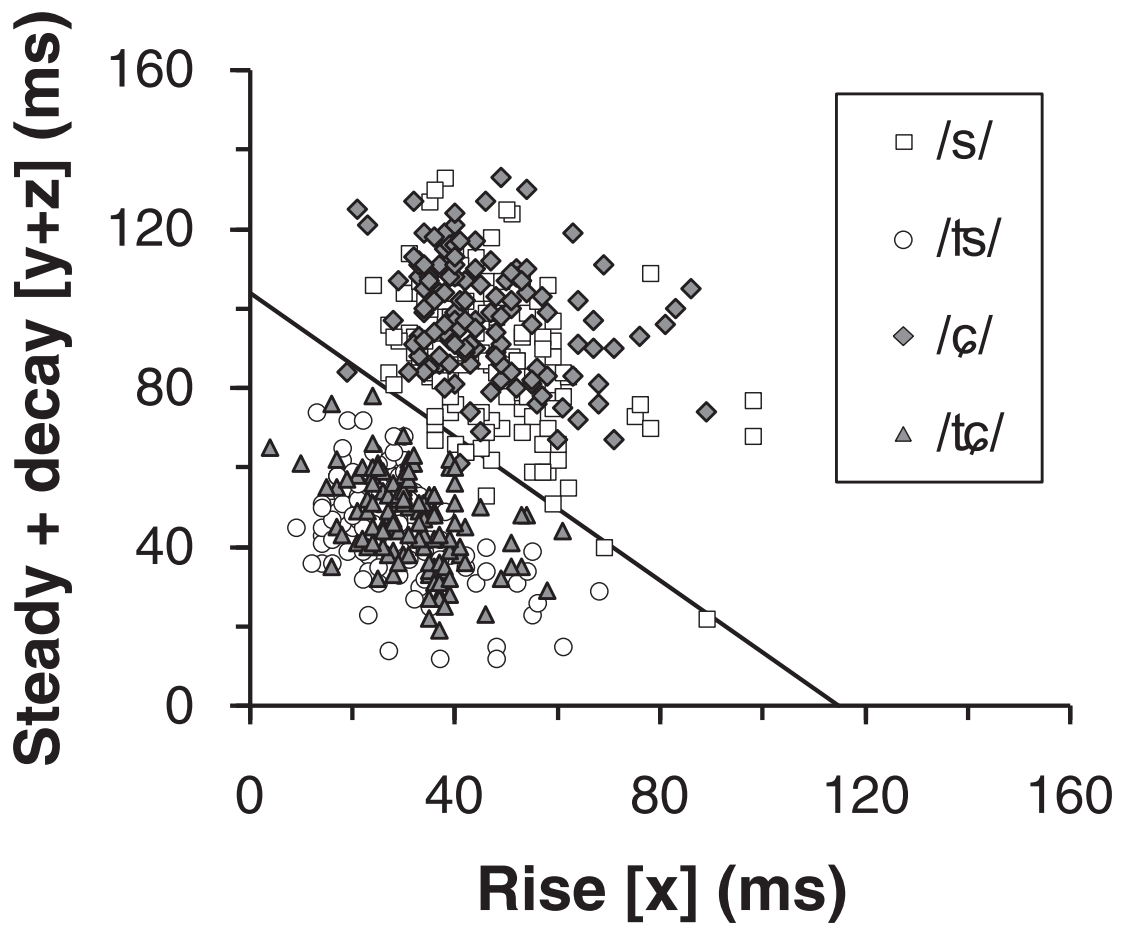

Fig. 2 Scattergram of production data of $/ \mathrm{s} /, / \mathrm{ts} /, / 6 /$, and $/ \mathrm{t}_{6} /(n=508)$. The horizontal axis is the rise duration and the vertical axis is the sum of steady and decay durations. The solid line represents the production boundary between fricatives $(/ \mathrm{s} /$ and $/ \mathrm{ts} /)$ and affricates $\left(/ 6 /\right.$ and $\left./ \mathrm{t}_{6} /\right)$.

$/ t_{6} /$. In this consonant pair analysis, the independent variables were $x$ and $y+z$, and the dependent variable was one consonant pair from among $/ \mathrm{s} /-/ 6 /, / \mathrm{s} /-/ \mathrm{ts} /$, /s/-/t, $/, / 6 /-/ \mathrm{ts}_{\mathrm{s}}, / \mathrm{c} /-/ \mathrm{t}_{6} /$, and $/ \mathrm{ts}_{\mathrm{s}} /-/ \mathrm{t}_{6} /$.

Discriminant analyses were also conducted for consonant groups. In the consonant group analysis, the independent variables were $x$ and $y+z$ and the dependent variable was a consonant group consisting of either fricatives $(/ \mathrm{s} /$ and $/ 6 /)$ and affricates (/ts/ and $\left./ \mathrm{t}_{6} /\right)$, or alveolar consonants (/s/ and /ts/) and alveolo-palatal consonants $\left(/ 6 /\right.$ and $\left./ \mathrm{t}_{6} /\right)$.

\subsection{Results and Discussion}

Figure 2 shows a scattergram of $/ \mathrm{s} /, / 6 /, / \mathrm{ts} /$, and $/ \mathrm{t}_{6} /$ on the " $x "-“ y+z$ " plane.

In the consonant pair analysis, the discriminant ratio was very high for $/ \mathrm{s} /-/ \mathrm{s} /(99.2 \%), / \mathrm{s} /-/ \mathrm{t}_{6} /(98.0 \%)$, $/ 6 /-/$ ts/ $(99.2 \%)$, and /6/-/t6/ $(99.2 \%)$. In contrast, the discriminant ratio was low for $/ \mathrm{s} /-/ 6 /(63.4 \%)$ and $/ \mathrm{ts} /-/ \mathrm{t}_{6} /(61.0 \%)$. These results indicate that the variables $x$ and $y+z$ are suitable for the discrimination of the four consonant pairs of $/ \mathrm{s} /-/ \mathrm{ts} /, / \mathrm{s} /-/ \mathrm{t}_{\mathrm{c}} /, / \mathrm{c} /-/ \mathrm{ts} /$, and $/ 6 /-/ t_{6} /$, but not of the two consonant pairs of $/ \mathrm{s} /-/ 6 /$ and $/ \mathrm{ts} /-/ \mathrm{t}_{6} /$. Focusing on $/ 6 /$ in these results, $/ 6 /$ was discriminated from affricates (/ts/ and $/ \mathrm{t}_{6} /$ ), but not from fricative /s/ when using the variables in the time domain, as predicted in the introduction.

In the consonant group analysis, the discriminant ratio between fricatives $(/ \mathrm{s} /$ and $/ 6 /)$ and affricates (/ts/ and $\left./ t_{6} /\right)$ was very high $(98.0 \%)$. In contrast, the discriminant ratio between alveolar consonants $(/ \mathrm{s} /$ and $/ \mathrm{ts} /)$ and alveolo-palatal consonants $(/ 6 /$ and $/$ to $/$ ) was low and almost at the level of chance (52.8\%). These results indicate that, using variables $x$ and $y+z$, fricatives and affricates can be discriminated, whereas alveolar and alveolo-palatal consonants cannot.

The discriminant function between the fricatives and the affricates was obtained as

$$
f_{\text {time }}=-0.263 x-0.290(y+z)+30.2,
$$

where $f_{\text {time }}$ is the discriminant score, $x$ is the rise duration (ms), and $y+z$ is the sum of steady and decay durations $(\mathrm{ms})$. By assigning zero to $f_{\text {time }}$ in Eq. (1), the production boundary between fricatives $(/ \mathrm{s} /$ and $/ 6 /)$ and affricates (/ts/ and / $/ \mathrm{t}_{6} /$ ) was obtained as

$$
(y+z)=-0.907 x+104 .
$$

The solid line in Fig. 2 represents the production boundary (Eq. (2)) between fricatives (/s/ and /6/) and affricates (/ts/ and / t $6 /$ ).

\section{SPECTRAL-DOMAIN ANALYSIS}

\subsection{Speech Materials}

The same speech materials as in the time-domain analysis (Sect. 2) were used in the spectral-domain analysis. 


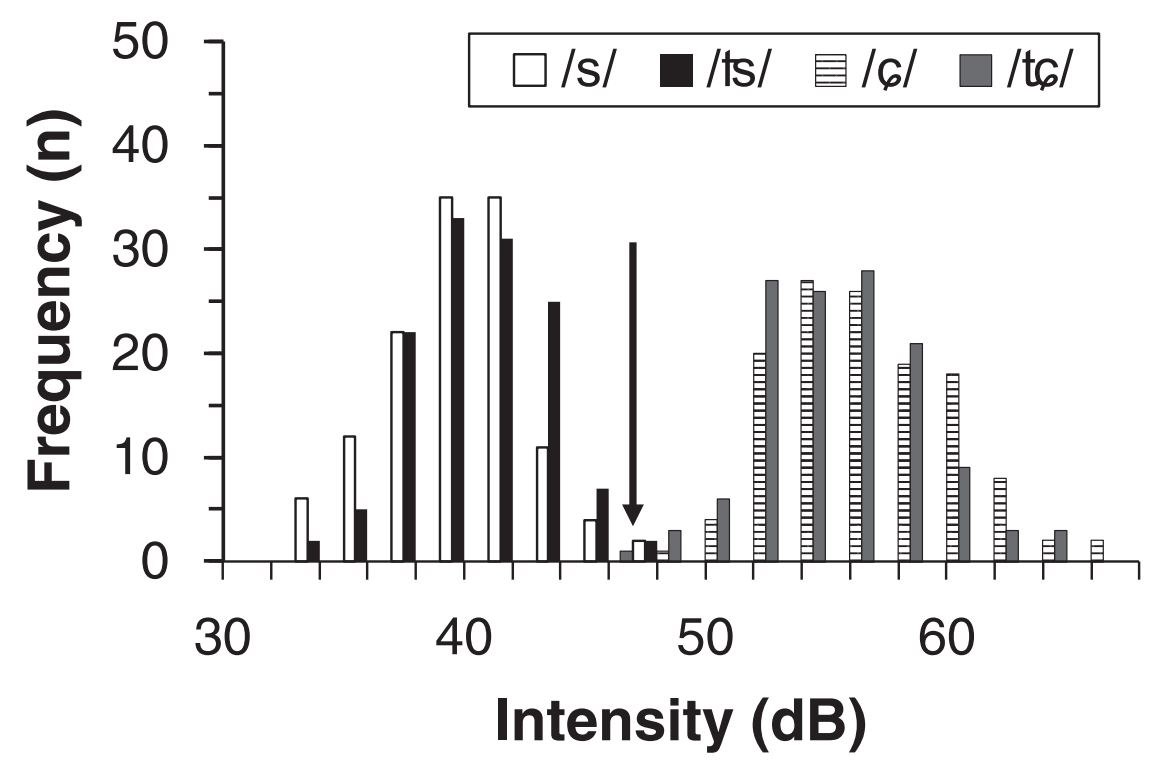

Fig. 3 Histogram of production data of $/ \mathrm{s} /, / \mathrm{ts} /, / 6 /$, and $/ \mathrm{t}_{6} /$ as a function of the mean intensity of the one-third-octave bandpass filter with a center frequency of $3,150 \mathrm{~Hz}(n=508)$. The arrow represents the production boundary between alveolar consonants (/s/ and /ts/) and alveolo-palatal consonants $\left(/ 6 /\right.$ and $\left./ \mathrm{t}_{6} /\right)$.

\subsection{Procedure}

The method proposed by Yamakawa and Amano [9] was applied to conduct the spectral-domain analysis because they showed that their method can discriminate affricates $/ \mathrm{ts} /$ and $/ \mathrm{t}_{6} /$ well. In this method, the mean intensity for the entire frication of $/ \mathrm{s} /, / \mathrm{c} /, / \mathrm{s} /$, and $/ \mathrm{t}_{6} /$ was computed by averaging the output of the one-thirdoctave bandpass filter with a center frequency of $3,150 \mathrm{~Hz}$. The mean intensity was expressed in $\mathrm{dB}$ with $10^{-10}$ as an arbitrary reference level.

The discriminant analyses were conducted for every combination of two consonants from the set /s/, /6/, /ts/, and $/ t_{6} /$. In this consonant pair analysis, the independent variable was the mean intensity at the one-third-octave bandpass filter with a center frequency of $3,150 \mathrm{~Hz}$, and the dependent variable was one of the following consonant pairs: /s/-/6/, /s/-/ts/, /s/-/t6/, /6/-/ts/, /6/-/t6/, or $/ \mathrm{ts} /-/ \mathrm{t}_{6} /$.

Discriminant analyses were also conducted for a consonant group. In the consonant group analysis, the mean intensity at the one-third-octave bandpass filter with a center frequency of $3,150 \mathrm{~Hz}$ served as the independent variable, and the dependent variable was a consonant group consisting of either fricatives $(/ \mathrm{s} /$ and $/ 6 /)$ and affricates (/ts/ and $\left./ \mathrm{t}_{6} /\right)$, or alveolar consonants $(/ \mathrm{s} /$ and $/ \mathrm{ts} /)$ and alveolo-palatal consonants $\left(/ 6 /\right.$ and $\left./ \mathrm{t}_{6} /\right)$.

\subsection{Results and Discussion}

Figure 3 shows a histogram of $/ \mathrm{s} /, / 6 /, / \mathrm{ts} /$, and $/ \mathrm{t}_{6} /$ as a function of the mean intensity at the $3,150 \mathrm{~Hz}$ onethird-octave band.
In the consonant pair analysis, the discriminant ratio was very high for $/ \mathrm{s} /-/ 6 /(99.6 \%), / \mathrm{s} /-/ \mathrm{t}_{6} /(98.8 \%)$, $/ 6 /-/ \mathrm{ts} /(99.2 \%)$, and $/ \mathrm{ts} /-/ \mathrm{t}_{6} /(99.2 \%)$. However, the discriminant ratio was low for $/ \mathrm{s} /-/ \mathrm{ts} /(54.3 \%)$ and $/ 6 /-/ t_{6} /(53.9 \%)$. These results indicate that the variable of the mean intensity at the $3,150 \mathrm{~Hz}$ one-third-octave band is suitable for the discrimination of the four consonant pairs of $/ \mathrm{s} /-/ 6 /, / \mathrm{s} /-/ \mathrm{t}_{6} /, / 6 /-/ \mathrm{ts} /$, and $/ \mathrm{ts} /-/ \mathrm{t}_{6} /$, but not for the discrimination of the two consonant pairs of $/ \mathrm{s} /-/ \mathrm{ts} /$ and $/ 6 /-/ t_{6} /$. Focusing on $/ 6 /$ in these results, $/ 6 /$ was discriminated from alveolar consonants $(/ \mathrm{s} /$ and $/ \mathrm{ts} /)$ but not from alveolo-palatal consonant / t $6 /$ when using the variable in the spectral domain, as predicted in the introduction.

In the consonant group analysis, the discriminant ratio between fricatives $(/ \mathrm{s} /$ and $/ 6 /)$ and affricates $(/ \mathrm{ts} /$ and $\left./ t_{6} /\right)$ was low and at the level of chance $(50.0 \%)$. In contrast, the discriminant ratio between alveolar consonants $(/ \mathrm{s} /$ and $/ \mathrm{ts} /)$ and alveolo-palatal consonants $(/ 6 /$ and $/ t_{6} /$ ) was very high (99.2\%). These results indicate that alveolar and alveolo-palatal consonants are well separated using the variable of the mean intensity at the $3,150 \mathrm{~Hz}$ one-third-octave band, but fricatives and affricates are not.

The discriminant function between the alveolar and alveolo-palatal consonants was obtained as

$$
f_{\text {spectrum }}=I-47.2 \text {, }
$$

where $f_{\text {spectrum }}$ is the discriminant score, and $I$ is the mean intensity $(\mathrm{dB})$ at the one-third-octave bandpass filter with a center frequency of $3,150 \mathrm{~Hz}$. By assigning zero to $f_{\text {spectrum }}$ in Eq. (3), the production boundary between alveolar 
consonants (/s/ and /ts/) and alveolo-palatal consonants $\left(/ 6 /\right.$ and $\left./ t_{6} /\right)$ was obtained as

$$
I=47.2 \text {. }
$$

The arrow in Fig. 3 represents the production boundary (Eq. (4)) between alveolar consonants (/s/ and /ts/) and alveolo-palatal consonants $(/ 6 /$ and / $6 / 6$ ).

\section{TIME- AND SPECTRAL-DOMAIN ANALYSES}

\subsection{Speech Materials}

The same speech materials as used in the time-domain analysis (Sect. 2) were used in the time- and spectraldomain analyses.

\subsection{Procedure}

The rise duration $x$ and the sum of steady and decay durations $y+z$ were calculated for each consonant in the speech material by the same procedure as applied in the time-domain analysis. The mean intensity of the one-thirdoctave bandpass filter with a center frequency of $3,150 \mathrm{~Hz}$ was also calculated for each consonant by the same procedure as in the spectral-domain analysis. By assigning these values to the discriminant functions in the time domain (Eq. (1)) and the spectral domain (Eq. (3)), the discriminant scores $\left(f_{\text {time }}\right.$ and $\left.f_{\text {spectrum }}\right)$ were calculated for each consonant. The consonant category $(/ \mathrm{s} /, / 6 /, / \mathrm{ts} /$, and $/ t_{6} /$ ) was identified for each consonant in the speech material referring to the $2 \times 2$ sign combination of the discriminant scores. That is, if $f_{\text {time }}<0$ and $f_{\text {spectrum }}<0$, the consonant was identified to be $/ \mathrm{s} /$, if $f_{\text {time }}<0$ and $f_{\text {spectrum }} \geqq 0$, the consonant was identified to be $/ 6 /$, if $f_{\text {time }} \geqq 0$ and $f_{\text {spectrum }}<0$, the consonant was identified to be $/$ ts $/$, and if $f_{\text {time }} \geqq 0$ and $f_{\text {spectrum }} \geqq 0$, the consonant was identified to be $/ t_{6} /$. Note that this procedure with Eqs. (1) and (3) is equivalent to the consonant identification referring to the production boundaries in the time domain (Eq. (2)) and in the spectral domain (Eq. (4)).

\subsection{Results and Discussion}

Table 1 displays the accuracy rate of the identification of each consonant referring to the production boundaries of Eqs. (2) and (4). Although there was a small error $(6.3 \%)$ where /s/ was confused with /ts/, the segments /s/, /6/, /ts/, and / t6/ were identified with more than $90 \%$ accuracy. The overall accuracy rate of identification was $97.2 \%(n=508)$ for the four consonants. This high accuracy rate indicates that the four consonants $/ \mathrm{s} /, / 6 /$, $/ \mathrm{ts} /$, and / 6 / were well separated by the combination of the production boundaries in the time domain (Eq. (2)) and in the spectral domain (Eq. (4)). This means that the four consonants are distinguishable on the basis of their acoustic features of $x$ and $y+z$ in the time domain and the mean
Table 1 Accuracy rate of identification (\%) of four consonants referring to the production boundaries in time and spectral domains.

\begin{tabular}{crrrr}
\hline \multirow{2}{*}{$\begin{array}{c}\text { Produced } \\
\text { consonant }\end{array}$} & \multicolumn{4}{c}{ Identified consonant } \\
\cline { 2 - 5 } & \multicolumn{1}{c}{$/ \mathrm{s} /$} & \multicolumn{1}{c}{$/ 6 /$} & \multicolumn{1}{c}{$/ \mathrm{ts} /$} & $/ \mathrm{t}_{6} /$ \\
\hline /s/ & 92.9 & 0.8 & 6.3 & 0.0 \\
$/ 6 /$ & 0.8 & 97.6 & 0.0 & 1.6 \\
$/ \mathrm{ts} /$ & 0.0 & 0.0 & 99.2 & 0.8 \\
/t6/ & 0.0 & 0.0 & 0.8 & 99.2 \\
\hline
\end{tabular}

intensity at the $3,150 \mathrm{~Hz}$ one-third-octave band in the spectral domain.

\section{GENERAL DISCUSSION}

Previous studies have shown that alveolar fricative /s / and alveolar affricate /ts/ are distinguishable using variables in the time domain [8], and that alveolar affricate /ts/ and alveolo-palatal affricate / t6/ are distinguishable using a variable in the spectral domain [9]. This study provided new findings for demonstrating that alveolopalatal fricative $/ 6 /$ is well separated from the affricates (/ts/ and / t $6 /$ ) with respect to the time-domain variables (Sect. 2), and from alveolar consonants (/s/ and /ts/) when using the variable in the spectral domain (Sect. 3).

In addition, for the consonant groups with the four consonants $/ \mathrm{s} /, / 6 /, / \mathrm{ts} /$, and $/ \mathrm{t}_{6} /$, we found that fricatives (/s/ and /6/) and affricates (/ts/ and / t6/) are well separated by a variable in the time domain (Sect. 2), and that alveolar consonants (/s/ and /ts/) and alveolo-palatal consonants $\left(/ 6 /\right.$ and $\left./ t_{6} /\right)$ are well separated by a variable in the spectral domain (Sect. 3). It can be said that the time-domain variable is associated with the manner of articulation, whereas the spectral-domain variable is associated with the place of articulation. These results extended the previous findings concerning /s/, /ts/, and $/ t_{6} /$ in the time and spectral domains [8,9], and integrated the findings for individual consonant pairs to the level of consonant groups, such as affricate vs fricative and alveolar vs alveolo-palatal.

Moreover, in this study, we found that the four consonants $/ \mathrm{s} /, / 6 /, / \mathrm{ts} /$, and $/ \mathrm{t}_{\mathrm{c}} /$ are well identified using a combination of production boundaries (Eqs. (2) and (4)) in the time and spectral domains (Sect. 4). This suggests that acoustic features of the four consonants are represented by the time-domain variables $(x$ and $y+z$ in Eq. (2)) and the spectral-domain variable ( $I$ in Eq. (4)). These findings would be applicable to a computer-aided education system for utterance training for non-native Japanese speakers. As previously discussed, non-native Japanese speakers often confuse the pronunciations of the four consonants $/ \mathrm{s} /, / \mathrm{c} / \mathrm{h} / \mathrm{ts} /$, and $/ \mathrm{t}_{\mathrm{c}} /$ in pronunciation. Therefore, a computer-aided education system that auto- 
matically classifies consonants pronounced by non-native Japanese speakers according to the production boundaries specified in this study would be highly useful, since feedback to non-native Japanese speakers would indicate whether or not their pronunciation is correct.

Although we obtained clear results with regard to the discrimination of the four consonants in the time and spectral domains, results were obtained from speech material spoken by a single female Japanese speaker. Individual, gender, and age differences in speech production might affect consonant discrimination. Speaking-rate and speech intensity differences might also affect consonant discrimination because it is probable that the durations $x$ and $y+z$ vary depending on the speaking rate, and the mean intensity of the one-third-octave bandpass filter varies depending on speech intensity. The following vowel might also affect consonant discrimination. Therefore, it is necessary to examine the effects of these features by analyzing the speech components of multiple speakers with various speaking rates, intensities, and following vowels. In these analyses, the consonants might be well classified using the time- and spectral-domain variables normalized by the speaking rate and the mean intensity, respectively, of the word.

The present study is concerned with the production of fricatives and affricates. It is unknown whether the perception of the fricatives and affricates relies on the variables in the time and spectral domains similarly to their production. However, some studies have showed perception to be dependent on at least the variables in the time domain. For instance, Howell and Rosen [7] demonstrated that the perceptions of $/ \mathrm{J} /$ and $/ \mathrm{t} /$ in English depend on the time-domain variable of the rise duration of frication. Mitani et al. [11] reported that the time-domain variables of the rise slope and the duration of frication contribute to the perceptions of $/ 6 /$ and $/ t_{6} /$. Yasu et al. [12] showed that perceptions of $/ 6 /$ and $/ t_{6} /$ in Japanese depend on time-domain variables of the closure duration and the rise and steady durations in frication. However, the contribution of the spectral-domain variables to the perception of fricatives and affricates has not been well studied. In future research, we should examine whether the fricatives and affricates are perceptually distinguishable using the boundaries represented by the time- and spectral-domain variables. We should also examine whether perception and production boundaries for fricatives and affricates coincide in order to better clarify the relationships between speech perception and production.

In summary, we analyzed the acoustic features of $/ \mathrm{s} /$, $/ 6 /, / \mathrm{ts} /$, and $/ \mathrm{t}_{6} /$ spoken by a female native speaker of Japanese. It was found that fricatives $(/ \mathrm{s} /$ and $/ 6 /)$ and affricates (/ts/ and / t $6 /$ ) are well separated when using a time-domain discriminant function, whereas alveolar con- sonants (/s/ and /ts/) and alveolo-palatal consonants (/6/ and $/ t_{6} /$ ) are well separated by using a spectral-domain discriminant function. It was also found that the four consonants are well distinguished by a combination of the time-domain and spectral-domain discriminant functions. Although this is a case study of a single native speaker, the results suggest that the acoustic features of the four consonants are probably represented by the time- and spectral-domain variables.

\section{ACKNOWLEDGMENTS}

This study was supported by JSPS KAKENHI Grant Numbers 22720173, 24652087, 25284080, and 26370464, and by a special-research grant (2013-2014) and cooperative-research grant (2013-2014) of Aichi Shukutoku University. This study was also supported by the NINJAL Core collaborative research project "Foundations of Corpus Japanese Linguistics."

\section{REFERENCES}

[1] Y. Sukegawa, "Bogobetsu ni mita hatsuon no keikou [Utterance tendency of non-native Japanese speakers]," Nihongo onsei to Nihongo kyoiku [Japanese Speech and Education], Research Report of Grant-in-Aid for Scientific Research on Priority Areas by Ministry of Education, Science and Culture, pp. 187-244 (1993) (in Japanese).

[2] K. Yamakawa, "Pronunciation characteristics of Japanese affricate /ts/ by Japanese learners: In case of Thais," Proc. Int. Conf. Japanese Language Education, Vol. 2, pp. 326-329 (2008).

[3] K. Yamakawa, Y. Chisaki and T. Usagawa, "Subjective evaluation of Japanese voiceless affricate spoken by Korean," Acoust. Sci. \& Tech., 27, 236-238 (2006).

[4] P. Strevens, "Spectra of fricative noise in human speech," Lang. Speech, 3, 32-49 (1960).

[5] A. Jongman, R. Wayland and S. Wong, "Acoustic characteristics of English fricatives," J. Acoust. Soc. Am., 108, 12521263 (2000).

[6] K. Maniwa, A. Jongman and T. Wade, "Acoustic characteristics of clearly spoken English fricatives," J. Acoust. Soc. Am., 125, 3962-3973 (2009).

[7] P. Howell and S. Rosen, "Production and perception of rise time in the voiceless affricate/fricative distinction," J. Acoust. Soc. Am., 73, 976-984 (1983).

[8] K. Yamakawa, S. Amano and S. Itahashi, "Variables to discriminate affricate / ts / and fricative /s/ at word initial in spoken Japanese words," Acoust. Sci. \& Tech., 33, 154-159 (2012).

[9] K. Yamakawa and S. Amano, "A variable to discriminate voiceless affricates at word initial in read and spontaneous Japanese speech," J. Phonet. Soc. Jpn., 18, 40-44 (2014).

[10] S. Amano and T. Kondo, Nihongo no Goi-tokusei [Lexical properties of Japanese], Vol. 1 (Sanseido, Tokyo, 1999).

[11] S. Mitani, T. Kitama and Y. Sato, "Voiceless affricate/ fricative distinction by frication duration and amplitude rise slope," J. Acoust. Soc. Am., 120, 1600-1607 (2006).

[12] K. Yasu, T. Arai, K. Kobayashi and M. Shindo, "Identification of voiceless fricatives/affricates by elderly listeners: Effect of degradation of auditory properties," J. Acoust. Soc. Jpn. (J), 68, 501-512 (2012) (in Japanese). 